\section{Perspectiva interdisciplinaria \\ en extensión. Un desafío \\ para la construcción de ciudadanía}

María Laura Marelli / Viviana Marucci / Rita Masi

Docentes de la carrera de Trabajo Social de la Facultad de

Ciencias Jurídicas y Sociales. Universidad Nacional del Litoral.

Pretendemos aportar al debate acerca de cómo la relación dialéctica disciplina-interdisciplina interviene en la construcción participativa de lo público, transformándose ésta de aparente debilidad en su principal riqueza.

A partir de la demanda de la vecinal de un barrio del borde noroeste de la ciudad de Santa Fe en cuanto a construir una caracterización de su población que permita diseñar, participativamente, políticas institucionales transformadoras, se desencadenó un Proyecto de Extensión de la Cátedra Metodología I, carrera de Licenciatura en Sociología y Ciencias Políticas, Facultad de Humanidades y Ciencias, en conjunto con la carrera de Licenciatura en Trabajo Social, Facultad de Ciencias Jurídicas y Sociales, ambas pertenecientes a la Universidad Nacional del Litoral.
Construir ciudadanía /

Intervenciones
En virtud de la densidad demográfica del barrio, durante el período 2008 y 2009 se diseñó e implementó el primer proyecto de extensión: "Relevamiento sociodemográfico, Vecinal Domingo F. Sarmiento, ciudad de Sta. Fe, Pcia. de Santa Fe", para el cual se seleccionó sólo un recorte del territorio. El mismo se implementó desde una metodología cuantitativa, de carácter exploratorio. En diálogo y coordinación permanente con la Comisión Directiva de la Vecinal Sarmiento del barrio Cabal, se identificó como una de las principales problemáticas la escasa participación de los vecinos en la gestión comunitaria, como también la insuficiente articulación entre las numerosas instituciones barriales. Esto trae como consecuencia la fragmentación de las acciones institucionales y transforma la cantidad de propuestas en obturación de procesos de participación y

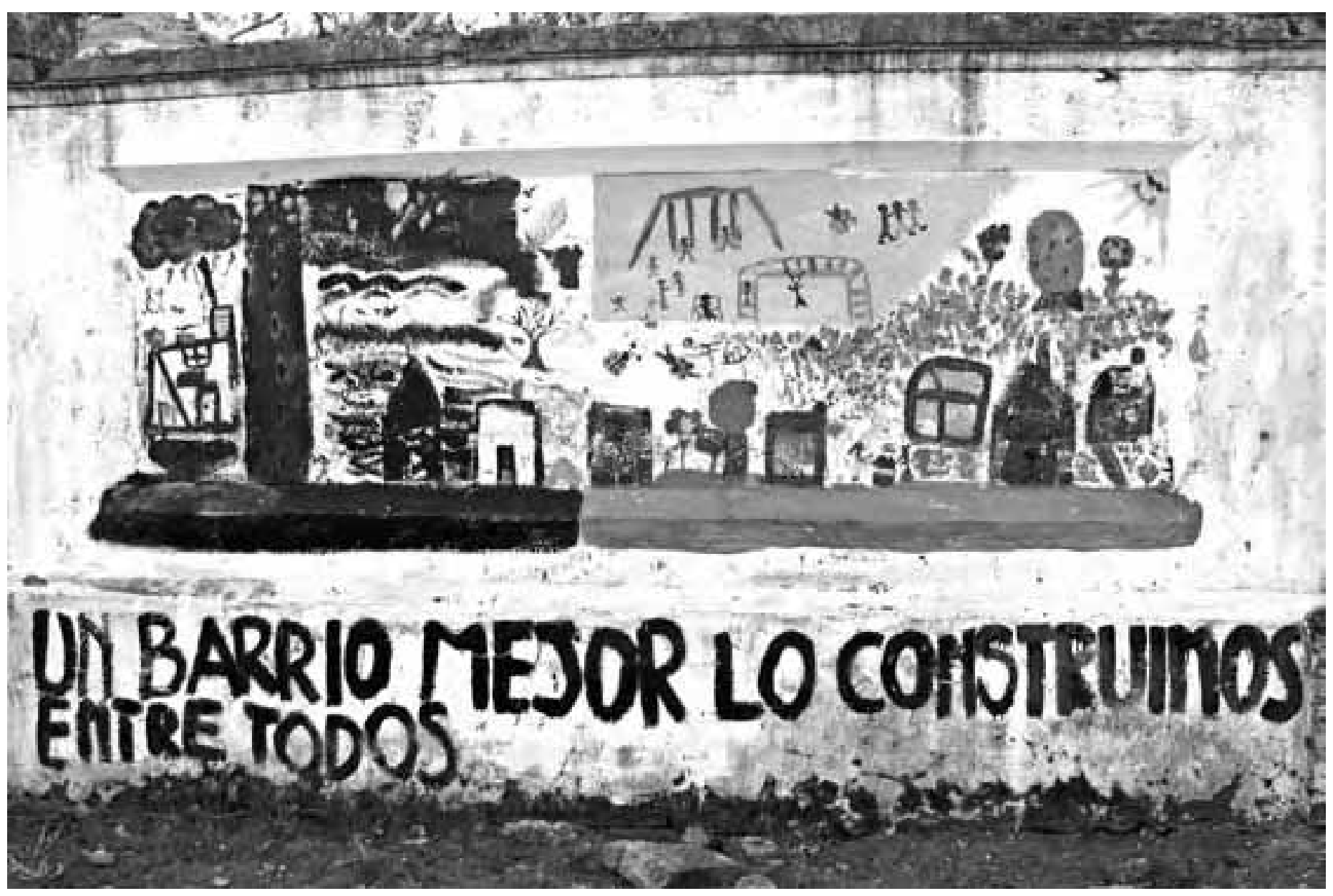




\section{C6 \\ la intencionalidad de este proyecto estuvo puesta en contribuir a desarrollar y fortalecer la capacidad institucional de la vecinal}

empoderamiento de los vecinos como sujetos políticos, proceso que se ve acentuado por las acciones clientelares de los distintos agentes político-partidarios que operan en el barrio.

Se verifica entonces la existencia de una ciudadanía que adquiere características de pasiva o de baja densidad, en la cual los habitantes sólo son destinatarios de los servicios institucionales pero no participan en la toma de decisiones y en la construcción de las políticas directrices de las mismas. Surge así un desafío, una tarea a emprender vinculada a propiciar un tránsito hacia una ciudadanía activa, construida en procesos conjuntos, habilitadora de la "palabra y la acción", y que se proponga trascender los límites territoriales.

En este sentido, la Vecinal Sarmiento, desde la óptica de la nueva gestión, tiene como uno de sus lineamientos prioritarios que los vecinos no sólo sean destinatarios de los servicios que allí se brindan sino que formen parte activa de los espacios institucionales en todas sus dimensiones, a efectos de transformar conjuntamente las problemáticas actuales del barrio.

Esta institución motoriza la consolidación de un espacio articulador que vincule a la mayor cantidad de instituciones comunitarias y también lidera la búsqueda de agentes externos que colaboren en este proceso desde diversas dimensiones. En este caso, entiende que la Universidad puede acompañar sus procesos.

Este posicionamiento habilitó la continuidad de un segundo proyecto y permitió abarcar la totalidad territorial. El mismo se llevó a cabo durante el período 2009-2010, lo cual posibilitó afianzar el vínculo y el intercambio entre los integrantes de la vecinal y la Universidad, tanto docentes como estudiantes del segundo ciclo de las mencionadas carreras.

Se retomó de ese modo un proceso de debate y construcción conjunta en el que se recabaron datos de otro sector del barrio. Luego del procesamiento y análisis de los mismos, nos encontramos en la instancia de socialización con la comunidad y construimos una producción escrita que dio cuenta del proceso, en la que participaron todos los actores involucrados, atendiendo especialmente a que los datos más recientes sobre el barrio Cabal eran los provenientes del Censo de Población y Vivienda del año 2001, por lo que esta información hizo factible realizar un diagnóstico preciso de la situación sociodemográfica de la población más vulnerable y contribuyó al logro de una caracterización de la pobreza con su realidad multifacética. Los procesos constitutivos de los barrios se ven atravesados por condicionantes estructurales que dan cuenta de la lógica neoliberal imperante. Algunas manifestaciones de la cuestión social se reflejan en la dinámica de los procesos migratorios y en el grado de riesgo en el que se encuentran los territorios expuestos a las cambiantes condiciones naturales y sociales.

Integrando este territorio particular, se identifica un sector que se configura sobre suelos de asentamiento producto del relleno de zonas de depresión. En tanto no existe una urbanización planificada desde el Estado, la producción social y física del hábitat ha sido resuelta por los propios vecinos de manera aleatoria, atendiendo a la urgencia de sus diversas necesidades.

Los mismos vecinos identifican sectores que no figuran en planos municipales y por lo tanto no pueden acceder a servicios públicos. La necesidad que se plantea desde la vecinal se relaciona con dar visibilidad a estas situaciones, al barrio como tal, a posicionarlo desde un conocimiento real del mismo. En palabras de la presidenta de la vecinal: (necesitamos) "herramientas para decir que éste es nuestro barrio; nosotros vivimos acá, y éstas son nuestras necesidades (...) que el resto de la sociedad nos pueda ver. El aval de la Universidad es importante".

La intencionalidad de este proyecto estuvo puesta en contribuir a desarrollar y fortalecer la capacidad institucional de la vecinal con el establecimiento de un ámbito de análisis, debate e intercambio de propuestas entre el mundo académico y las instituciones barriales acerca de los temas relevantes respecto de la problemática social de sus habitantes.

La información obtenida posibilita sustentar científicamente la gestión de las instituciones que trabajan en el barrio, ya que identifican el obstáculo de carecer de información adecuada y confiable sobre el colectivo poblacional, con especial interés 
en identificar condiciones de vulnerabilidad, para el diseño de proyectos y programas de intervención.

La formación profesional, vinculada aquí con la extensión, nos interpela a habilitar nuevos modos de intervención social, donde el encuentro sistemático y sinérgico de múltiples saberes, que circulan en diferentes ámbitos, habilite el diálogo constituido en herramienta indispensable, posibilitador de transformación social, fundado en una racionalidad humanizante.

Desde esta perspectiva, concebimos la extensión universitaria, como una práctica social, sustentada en conocimientos teóricosmetodológicos, que responde a perspectivas epistemológicas y asume un compromiso ético-político con la realidad social, pensada desde las implicancias del "encuentro" con otros sujetos que significa su inserción en la realidad social.

A través de su participación activa en las distintas instancias que formaron parte de la implementación del proyecto de extensión, los miembros de la vecinal, específicamente integrantes del Comisión Directiva, manifestaron su involucramiento y compromiso en la tarea. Estuvieron presentes junto al equipo, aportaron en la difusión de la actividad concreta de relevamiento entre los vecinos y sus características y proporcionaron elementos para la construcción del instrumento desde los aspectos relevantes que les interesaban conocer y la realización de ejercicios de prueba del instrumento para constatar errores en su formulación previamente a la puesta en acto con los vecinos.

La figura de la Universidad (desde el abordaje interdisciplinario de Sociología, Ciencias Políticas y Trabajo Social), en este contexto, resulta un aporte significativo en la construcción de categorías de análisis para comprender y explicar una realidad compleja y dinámica y para hacerse de elementos y herramientas que posibiliten, desde la fragmentación imperante, construir una visión más totalizadora y abordar acciones concretas desde el espacio público que habiliten no sólo el reclamo sino la participación en el diseño de políticas públicas comunitarias. Por lo tanto, nos dimos un trabajo docente, previo a la implementación en sí del instrumento de recolección de datos, junto a los estudiantes de las carreras mencionadas, pensando una estrategia capaz de contribuir a la integración personal, como desde los saberes disciplinares, que enriqueciera todo el proceso.

Se planificaron instancias capaces de propiciar la puesta en tensión de los conocimientos teórico-metodológicos en situaciones concretas que problematizaran la dimensión ético-política de las profesiones. Las instancias pautadas resultaron altamente significativas, nos permitieron pensar la extensión en vinculación íntima con los procesos de formación profesional, donde se insta al estudiante a poner juego sus saberes, representaciones y habilidades, materializando un aporte a la comunidad-institución en la que se inserta.

Para llevar adelante este proceso, se apeló a la estrategia docente de taller, entendido éste como espacio de reflexión-problematización de la realidad, donde los sujetos participantes (docentes-estudiantes) puedan reconocerse como productores de la tarea.

Instalar como premisa el aprender a co-pensar junto con otros, cooperar, desarrollar actitudes de tolerancia y solidaridad que provoquen rupturas en la lógica individualista pero que rescaten la individualidad y el compromiso de aportar creativa y críticamente a la totalidad. La puesta en común de los saberes, necesidades e intereses, resultó ser la materia prima indispensable en la construcción de un proceso compartido, colectivo y democrático. Este espacio dio cuenta de la diversidad de saberes, siempre con la intención de evitar que se establezcan jerarquías, valorizando los aportes diferenciales desde la interacción a través de la participación activa de todos.

Considerando que cada uno requiere su propio tiempo reflexivo y que en todo proceso se producen avances y retrocesos, oscilaciones y dudas, es en este espacio donde es posible fortalecer una multiplicidad de aspectos que propician el aprendizaje, como son las vivencias, las emociones, la toma de la palabra, la discusión respetuosa y la acción.

Tanto el pensamiento como el sentimiento forman parte de estos procesos compartidos en tanto no se desarrollan naturalmente sino que se construyen desde iniciativas como ésta.

Cuando las temáticas abordadas interpelan la cotidianidad personal, familiar y comunitaria, se hacen presentes supuestos construidos socialmente bajo la forma de representaciones y prejuicios, entendidos como constructos individuales y sociales, pero a partir ellos que se logró llevar adelante un proceso de explicitación, desnaturalización y mirada crítica. Se instituyó un proceso enriquecido puesto que aconteció en interrelación con otros con quienes compartir y disentir, en un intento de poner en tensión los propios supuestos. Proceso, en definitiva, educativo para todos los intervinientes en cuanto transformador de subjetividades.

Estos talleres transitaron por distintos momentos de integración e intercambio de los participantes e hicieron posible la conexión con sus sentimientos, interpelaron sus juicios valorativos, sus prácticas, y pusieron a la luz las representaciones respecto de la pobreza, las necesidades, recursos y proyectos. Todo ello coincidente con el hecho de que la institución vecinal se erige como "punto de unión, referencia", como "refugio" y significación dentro de un contexto barrial, de construcción de una mirada teórica compartida, que potencia su creatividad e instala un pensamiento indagador, divergente y flexible, que propone nuevas categorías de análisis para una mayor inteligibilidad del escenario, teniendo como intención superar la dicotomía teoría-práctica, huellas de origen de las disciplinas participantes.

Remitiéndonos a los orígenes de las mismas, Sociología y Ciencias Políticas nacen al resguardo de la teoría como instancias productoras de conocimientos necesarios para comprender y actuar sobre la sociedad; mientras que Trabajo Social tiene un origen que se ubica en el polo opuesto de la dupla. Nace 


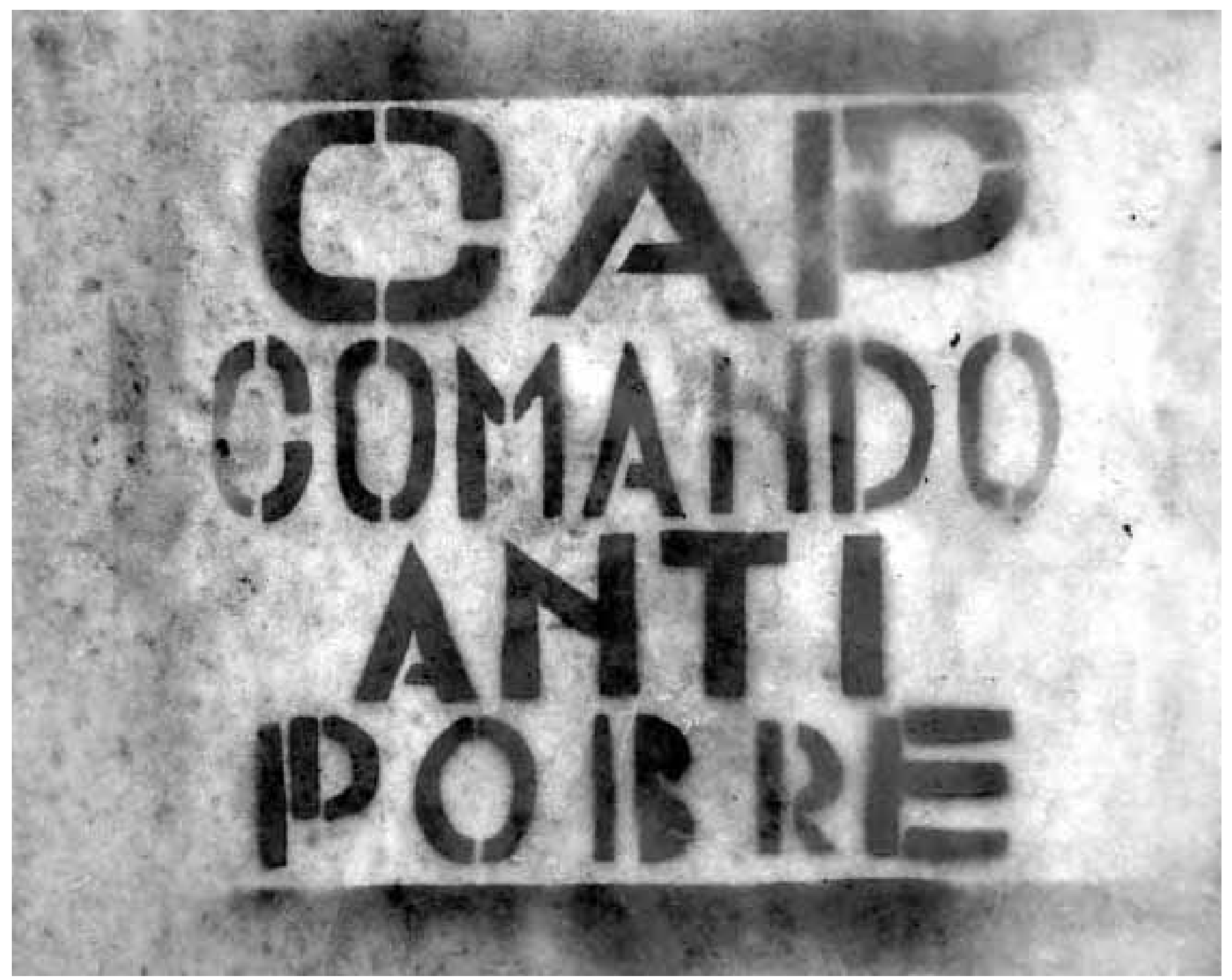

como mano operativa del Estado-nación para llevar adelante las políticas sociales. Esta experiencia sedimentó un espacio para la construcción y discusión del instrumento de relevamiento de datos, donde cada estudiante puso en escena sus debilidades y fortalezas como también sus intenciones de superarlas.

La instancia del reconocimiento territorial, previa al relevamiento, fue ocasión de intercambio y aprendizaje, permitió revisar el instrumento a la luz de la observación del escenario concreto. Dio lugar a pensarse en vinculación a categorías teóricas previamente abordadas: pobreza, vulnerabilidad, cuestión social, entre otras. La discusión del instrumento con los vecinos posibilitó interactuar e incorporar la mirada y los saberes de la propia población, la cual participó igualmente junto a los docentes de ambas cátedras. La encuesta construida de la manera descrita contiene variables referidas a la identificación del núcleo familiar y de la población, sus características sociodemográficas, incluyendo variables relacionadas con los aspectos educativo, ocupacional, de salud, programas sociales, características de la vivienda y servicios con que cuentan, grado de conocimiento y participación en las instituciones barriales, problemas comunitarios. El diseño de la matriz de datos y procesamiento, a través del software que posibilite la construcción del objeto del estudio, constituyó otro aspecto de este proceso de aprendizaje. Debido a lo imperativo de reforzar el conocimiento en cuanto a la producción de textos académicos, se pautó un encuentro con docentes de cátedra de Producción de Textos Académicos. La intencionalidad estuvo puesta en que los estudiantes adquirieran habilidades en la escritura científica y a la vez dejar plasmado un producto que diera cuenta de lo vivido y realizado, facilitando a los vecinos la apropiación de la información. 
Todo este trayecto estuvo acompañado por un estudiante de la carrera de cine, lo que hizo factible la realización de una producción audiovisual con el objetivo de no ser sólo en un aprendizaje en situación real (de contenidos teóricos y metodológicos asociados a la cátedra) sino con la mirada puesta en que la experiencia pueda proporcionar un anclaje que la exceda y posibilite procesos de inserción en las problemáticas sociales y en alternativas de intervención en ellas, lo que contribuye a una formación como profesionales comprometidos con el medio.

En tanto, se erige como función de la Universidad

"exponer el conjunto de conocimientos y hacer que aparezcan los principios al mismo tiempo que los fundamentos de todo saber, pues no existe capacidad científica creadora sin espíritu especulativo." (Schleiermacher, 1998:270)

Esta práctica encierra la riqueza de concretarse en la intersección de disciplinas de las Ciencias Sociales, que no siempre encuentran un lugar desde la formación profesional para interactuar y concretar un espacio de aproximación al campo de la futura intervención profesional.

La participación en este proyecto, en clave de proceso, pretendió dejar huellas para que los estudiantes construyeran otras maneras de poner tensión los conocimientos teóricos y prácticos que se imparten en las carreras, en contacto con una experiencia concreta de trabajo de campo, con otros: otros estudiantes, otros sectores sociales, otras instituciones, otros docentes, generando espacios que fortalezcan el lazo social, diseñando nuevos trayectos para apropiarse y posibilitar la apropiación de la trama de la ciudad. Estos encuentros tuvieron como objetivo construir nuevos saberes para elaborar una estrategia integral e innovadora atravesada por las dimensiones: teórico-epistemológica, metodológicoinstrumental y ético-política.

La interdisciplinariedad genera un aprendizaje significativo porque quienes lo constituyen pueden ser capaces de reconocer su propia acción y la de los otros, vinculándose con un modo singular de aprender a hacer, convivir, alcanzar nuevos conocimientos y expresarlos.

Ello se evidencia en la creación de estos espacios colaborativos, que potencien la participación de los estudiantes desde el compromiso, la actitud crítica, propositiva y de discernimiento, desdibujando los límites disciplinares, sin diluir la singularidad que le otorga carácter y que por lo tanto requiere el aporte de cada una de sus perspectivas a partir de la diversidad de vías de acceso a la realidad, confiriéndole así sentido a su multidimensionalidad y complejidad.

Este camino no es nuevo y ha sufrido rupturas y continuidades en esta relación dinámica entre la teoría y la práctica y entre las distintas disciplinas y profesiones. Esta experiencia posibilitó la visibilización y problematización constante de la tensión originaria entre teoría y práctica en pos de superar las marcas de origen de cada una de estas disciplinas. Las mismas se han ido constituyendo históricamente en representantes de cada uno de estos polos, construyendo prácticas y discursos, ya desde la formación profesional, que contribuyen a fragmentar aún más la realidad en la que el "experto" domina desde sus competencias todos los aspectos de un campo.

Es preciso entonces propiciar el estatuto de la carrera de Trabajo Social en el ámbito universitario, donde este diálogo con las otras disciplinas se realice desde un encuentro y no desde la subordinación. Subordinación históricamente asumida y combatida desde diferentes esferas para lograr que tanto estudiantes como docentes accedan a las mismas oportunidades de formación que otras disciplinas en el ámbito universitario. Aún hoy se continúa verificando en las intervenciones del trabajo social este carácter de subalternidad respecto de otras disciplinas con las que interactúa en su cotidiana labor. Si bien se han realizado grandes avances, estas continuidades no deben dejar de tensionarnos para abandonar la égida de las otras profesiones.

Sin desconocer el carácter interventivo del trabajo social y su compromiso con la defensa de los derechos humanos fundamentales, sostenemos que resulta imperioso que la formación académica de la profesión se concrete en el ámbito universitario. Aquí queremos dedicar un párrafo a destacar el proceso llevado adelante por la anterior Escuela de Servicio Social de Santa Fe, hoy carrera de Licenciatura en Trabajo Social de la Universidad Nacional del Litoral, lo cual significó el logro de un anhelo construido a lo largo de los más de 60 años de vida de nuestra institución y que fue concretado a fines del año 2010. Plantear un diálogo de igual a igual entre las carreras que formaron parte de este proyecto permitió reconocerse en las fortalezas y debilidades desde la formación profesional.

Algunos estudiantes de trabajo social expresan que, en la formación, se le está otorgando mayor relevancia a las metodologías cualitativas, mientras que a las cuantitativas se les destina menos tiempo y profundidad, lo cual ocasiona dificultades en las intervenciones y en las investigaciones profesionales, que los colocan en situación de desventaja frente a la formación del sociólogo y del cientista político. Se destaca así que, a partir de este proyecto de extensión, pudieron acercarse a las mismas y problematizar sobre los prejuicios de la lógica positivista con los que se encuentran impregnados, pero rescatando que estas herramientas como tales no tienen un fin en sí mismo, sino que el sentido le es otorgado por el sujeto. Es importante hacer visible que estos puntos de tensión también fueron objeto de debate en el diseño del nuevo plan de estudio de la Licenciatura en Trabajo Social que actualmente implementa la carrera.

Por otra parte, los estudiantes de las otras disciplinas reclaman poder contar en su formación de base con espacios de aprendizaje que se construyan desde anclajes territoriales, que les permitan acercarse al "otro", "conocer sus significaciones", los "sentidos de su acción", lo que identifican como falencia en su formación profesional. El desarrollo y la profundización de las metodologías cuantitativas, 
La interdisciplinariedad genera un aprendizaje significativo

porque quienes lo constituyen pueden ser capaces de reconocer su propia acción y la de los otros, vinculándose con un modo singular de aprender a hacer, convivir, alcanzar nuevos conocimientos y expresarlos.
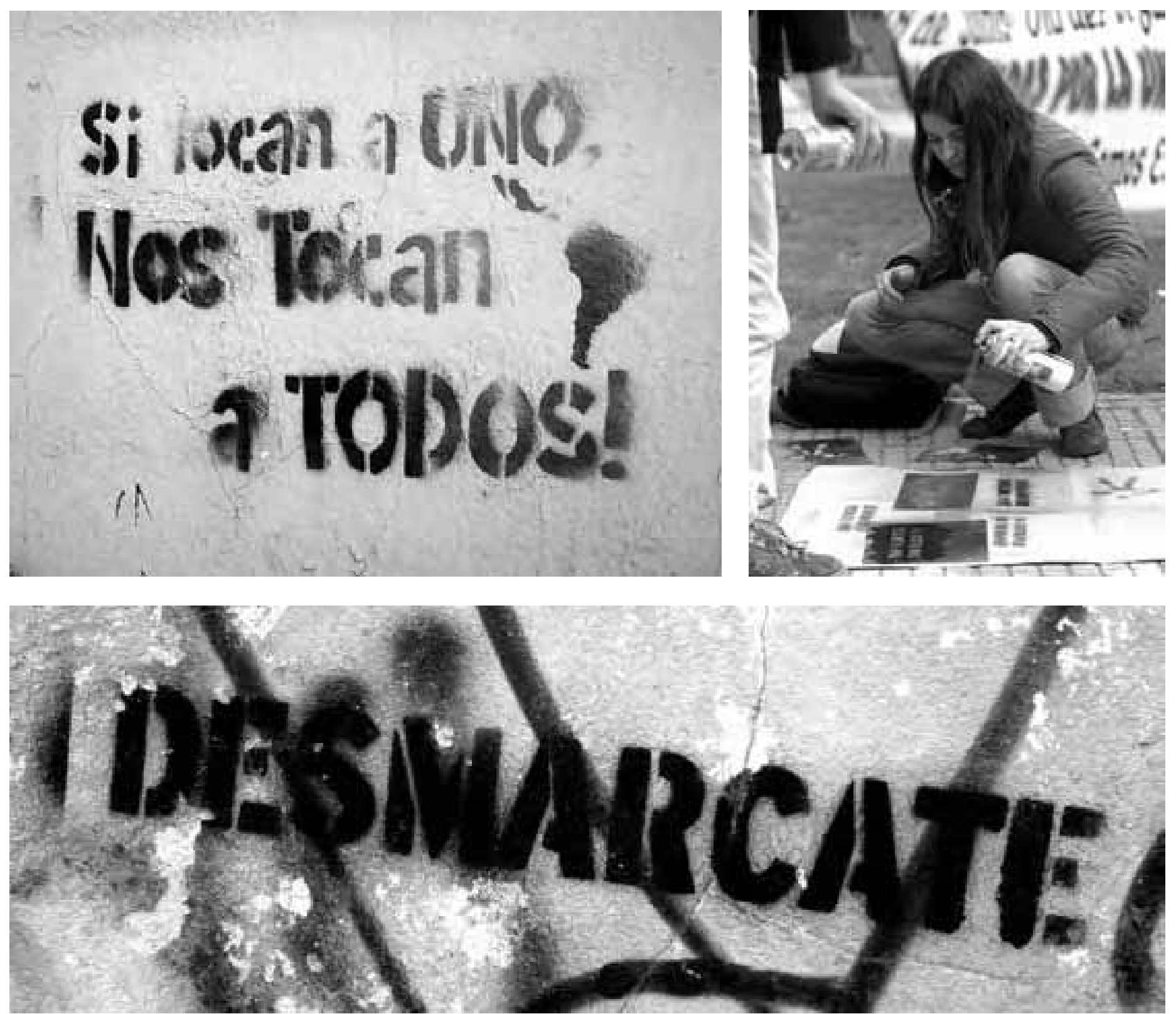
además de los docentes referentes del proyecto, contó con el acompañamiento del Observatorio Social, institución dependiente de la Universidad Nacional del Litoral que puso a disposición los docentes para la apropiación del software de carga de datos y las instalaciones edilicias y sus recursos para que los estudiantes concurran con el acompañamiento docente a hacer esta tarea. Algunas expresiones al respecto son: "El poder desarrollar destrezas y habilidades en el uso de ambos métodos nos permite realizar recortes analíticos y operativos frente a esta realidad tan compleja". "Otro aporte significativo de la experiencia, fue poder ir avanzando en la producción de textos académicos que nos permitan poner en escena nuestras posturas fundadas frente a las distintas manifestaciones de la cuestión social, desde lógica dialógica con distintos actores y diversos saberes." Dar cuenta de este proceso es rescatar la significación que algunos estudiantes le otorgaron al mismo: "La contribución de todas las miradas, el debatir y el poder consensuar fue enriquecedor". "Este proyecto nos permitió ampliar nuestros horizontes y generar nuevos modos de ver e interpretar la realidad."

Simultáneamente, se generaron fricciones entre los estudiantes de las otras disciplinas, como también en relación con los referentes de la vecinal, cuyas ideas de los saberes profesionales se encuentran asociadas a imágenes prefiguradas y poco flexibles. Mientras que el trabajo social se haya identificado con la asistencia a poblaciones vulnerables, el quehacer de los sociólogos y politólogos se encuentra vinculado a la producción de conocimiento científico y a funciones públicas.

Por ello, la implementación de este proyecto de extensión implicó generar estrategias en espacios de interlocución y evitar la naturalización de las representaciones sociales contenidas en cada discurso. Estas racionalidades coincidentes con las de la sociedad que las produce va sedimentando legitimaciones en acciones concretas, y es necesario hacerlas perceptibles para construir otra racionalidad. Sostenemos así que

"la interdisciplinaridad es la respuesta actual e imprescindible a la multiplicación, fragmentación y división de los conocimientos; proliferación y desmedido crecimiento de la información que, complejizando la complejidad en la que vivimos, se ha trasformado en algo estructural e irreversible." (Rodríguez Neira, 1997)

Se favorecieron fisuras en las construcciones de las fronteras disciplinarias tradicionales. La opción pedagógica da cuenta de un proceso de enseñanza y aprendizaje imbuido de una perspectiva interdisciplinaria y compleja, que habilite la legibilidad de los escenarios actuales como una totalidad relacional para la construcción de lo público. Apostamos a la creación de procesos de autonomía, espacios de participación interactoral, desde estrategias singulares e innovadoras, que fortalezcan la dimensión política de los sujetos. Entendemos, con Castoriadis, que sólo la educación (paideia) de los ciudadanos puede dar contenido verdadero y auténtico al "espacio público" asumiendo el compromiso de participación en la vida política desde la democratización de las relaciones sociales, ampliando y universalizando los derechos. Por ello es imperativo un compromiso con el saber en un contexto en el que la ciencia se encuentra compelida con los relatos que la estructuran, y se ponen en tensión la legitimación de las instituciones que sustentaban el lazo social.

Por eso el compromiso no debe ser sólo docente sino también ser compartido por los estudiantes para que pongan a disposición sus elaboraciones y conocimientos adquiridos en la experiencia, en vinculación con otras asignaturas, estimulando la participación en clave de ciudadanía. Compromiso con la formación y compromiso de intervención en la comunidad, que permite ampliar los horizontes de sentido, desestructurar la óptica desde la que son comprendidos los procesos sociales y, aún más, posibilita adentrarse en otras realidades que conviven en la misma ciudad y que se encuentran ocultas tras líneas invisibles. Éstas, al decir de Bauman, se constituyen en espacios no reconocidos, inexistentes en nuestros mapas mentales.

Estructurar nuevos mapas mentales, acompañados de procesos que eviten la fragmentación de la ciudad, en lugares que son evitados, eliminados de los trayectos por donde transcurren sus vidas cotidianas; dará lugar a erosionar fronteras impuestas de la mano de prácticas sociales potenciadoras de capacidades y libertades. Estos trayectos y sus convergencias evidencian la categorización de los espacios y suponen una sucesión de perspectivas de la ciudad, con sus ritmos, sus pausas, sus intercambios.

El espacio público adquiere así un lugar trascendental, donde los sentimientos de identidad y saberes comunes de la población en la creación de los mismos tienen una trascendencia histórica y establecen una imagen de la ciudad en su conjunto donde en ese interjuego de intereses y lucha de poderes se configura un campo de tensiones y conflictos, porque no todos lo conciben como un derecho sino como mercancía de lucro.

Desde esta tensión, los procesos sociales en tanto red de actores expresan una conflictividad social en la que los sectores que se encuentran ubicados en las zonas de vulnerabilidad social ven obturado su acceso a todos a los bienes producidos colectivamente y también son "separados", excluidos de la trama de la ciudad. Las imágenes de lo urbano son una construcción no acabada, sino que se van configurando en cambios y alteraciones a partir de nuevos elementos significativos. Acordamos con Davallon en la necesidad de contrarrestar la violencia simbólica, cultural, que los grupos dotados de poder social y económico son capaces de imponer sus intereses y sus gustos, asignando subrepticiamente sentido a los lugares.

Sin desconocer que somos producto de una sociedad, es imprescindible establecer un compromiso con esa realidad, lograr un distanciamiento crítico con ella para poder transformarnos en productores de nuevos modos de habitar, animados a la 
configuración de nuevas categorías para dar visibilidad y sustentar las demandas sociales.

Desde este país, que presenta tantas fragmentaciones, analizar las relaciones que se gestan en él nos impone el desafío de la multipertenencia y de pensar creativamente en sus cruces y articulaciones, donde el saber no se configura sólo como instrumento de poder sino que va entretejiendo instancias para que contengan nuestra perplejidad frente a un contexto avasallante, que intenta imponer su lógica de mercantilización y hace perder su propia finalidad para transformarse en objeto de disputa de poder. Se evidencia en la tensión existente entre las incumbencias profesionales que logran los estudiantes en el proceso de formación y las demandas del mercado laboral, por lo que el trabajo interdisciplinario se configura en un criterio preformativo. Esta tarea demanda tanto de parte de los docentes como de los estudiantes planificar acciones que den cuenta de la generación de producciones escritas a partir de los datos relevados, que sirvan como insumo para el debate en los talleres cuyos destinatarios serán los vecinos del barrio y las instituciones de la zona. De la misma manera, estas producciones deberán estar disponibles para directivos y técnicos de organismos públicos de programas y servicios sociales nacionales, provinciales y municipales. A partir de la socialización comunitaria de la información recabada en los dos relevamientos sociodemográficos realizados, se construirá un espacio de debate y reflexión que permita arribar, juntamente con la participación de las instituciones barriales, a un diagnóstico participativo para identificar y priorizar las problemáticas barriales, los recursos existentes y las estrategias de intervención más viables para dar resolución a los mismos.

Todo ello diseñado por medio de talleres donde se involucre a toda la comunidad, con la exigencia de flexibilidad necesaria para modificar o incorporar otras temáticas de interés que surjan en el proceso y elaborar proyectos y gestiones en el ámbito público. Apostamos, de esta forma, a la consolidación de un espacio interinstitucional de trabajo en red entre las instituciones comunitarias que tenga incidencia en la agenda pública, que potencie y empodere a los vecinos como sujetos de derechos. Se pretende dejar instaladas capacidades en los representantes de las instituciones y vecinos para que la presencia de la Universidad no resulte indispensable sino que ésta pueda retirarse habiendo "dejado huella", traducida en transformaciones y rupturas: en las miradas, en las formas de abordar los problemas comunes, y en las maneras de organizarse.

Este proceso ha transitado distintas instancias de evaluación y monitoreo, concibiéndolas como un insumo para la gestión, redefinición y resignificación de las acciones sociales, tendientes a superar los problemas que se presenten durante su ejecución. De la eficacia del sistema de seguimiento depende la agilidad y la oportunidad para trasmitir la información válida. De esta manera podrá incidir en la toma de decisiones tendientes a superar los problemas cuando sea necesario, volviendo las acciones sociales y de capacitación más eficientes.

Ésta intenta poner en valor y perfeccionar la conceptualización y el diseño, la implementación y la utilidad de las acciones de intervención social, utilizando en los distintos momentos, acorde con las necesidades del proyecto, distintas tipologías: diagnóstica, de proceso, de resultados, de impacto. Lo importante es la determinación del impacto del proyecto y su evaluación en función de las necesidades y valores de los actores involucrados. Es decir, poner en el debate la perspectiva de los actores involucrados tantas veces olvidada desde las instancias de planificación. Huir de la lógica positivista tan arraigada, en la cual también fuimos formados los docentes, que puja por reaparecer en escena y subsiste el paso del tiempo, precisa replanteos mayores e intencionalidades políticas, que incluyen el involucramiento de otros niveles decisorios que nos exceden como docentes, a pesar de contar con el apoyo de ambas instituciones.

\section{Bibliografia}

Augé, Marx (2000). Los no lugares. Espacios del anonimato. Una antropología de la sobremodernidad. Barcelona: Gedisa.

Bauman, Zygmunt (2000). Modernidad Liquida. Buenos Aires: FCE.

Castel, Robert (1997). La metamorfosis de la cuestión social. Una crónica del salariado. Madrid: Paidós.

Davallon, J. y Carrier, C. (1989). La presentation du patrimoine: communiquer, exposer, exploiter. Étude d'Expo Media pour le Ministère de la Culture. Francia. Gil de Arriba, Carmen (2002). Ciudad e Imagen: Un estudio geográfico sobre las representaciones sociales del espacio urbano de Santander. Cantabria: Ediciones de la Universidad de Cantabria.

Gravano, Ariel (2005). El barrio en la teoría social. Buenos Aires: Espacio. Lyotard, Jean (1987). La condición postmoderna. Informe sobre el saber. Francia: Ediciones de Minuit.

Montaño, Carlos (1998). La naturaleza del Servicio Social. Un ensayo sobre su génesis, su especificidad y su reproducción. Buenos Aires: Biblioteca Latinoamericana de Servicio Social.

Rodríguez Neira, Teófilo (1997). Interdisciplinariedad: Aspectos básicos. Madrid: Morata.

Schleiermacher, F. (1978). "Pensées de circonstance sur les universités de conception allemande." En Philosophies de I'Université. Francia.

Sennett, Richard (2000). La corrosión del carácter. Las consecuencias personales del trabajo en el nuevo capitalismo. Barcelona: Anagrama. Colección Argumentos. 